\title{
Experimental Investigation of a Novel Cathode Matrix Flow Field in Proton Exchange Membrane Fuel Cell
}

\author{
Bowen Wang, ${ }^{\#}$ Xiaoyan Sun, ${ }^{\#}$ Xu Xie, Jianan Wang, Lincai Li and Kui Jiao*
}

\begin{abstract}
Scaling relations The flow field design is critical for the proton exchange membrane fuel cell optimization, and a novel cathode matrix flow field is experimentally investigated in this work. The results show that the cell with the matrix flow field has better performance than that with the conventional parallel and serpentine flow fields, especially at high relative humidity (75\% higher current density at $0.6 \mathrm{~V}$ and $100 \%$ relative humidity). Furthermore, the pressure drop of the matrix flow field is much less than that of the serpentine flow field. But the matrix flow field shows worse liquid discharge capacity than the serpentine flow field. Decreasing the single block area in the investigated range will increase the ohmic loss but greatly decrease the activation loss that highlights the advantages of the matrix flow field. For visualization of water discharge, the smaller single block leads to more water accumulation at the corners of the flow field. Therefore, sub-regions and compulsive gas distribution should be considered if the matrix flow field is applied in large-scale fuel cells. The matrix flow field with the compact block arrangement shows reduced ohmic and activation losses by the large conductive area and enhanced air guidance effect in the investigated range.
\end{abstract}

Keywords: Anomalous heat conduction; Low-dimensional systems; Stochastic entropy production; Fluctuating hydrodynamics; Stochastic thermodynamics.

Received: 16 November 2020; Accepted: 3 December 2020.

Article type: Research article.

\section{Introduction}

With the increasingly serious problems of environmental pollution caused by fuel usage, the development of clean energy becomes urgent. ${ }^{[1,2]}$ Proton exchange membrane (PEM) fuel cells have advantages of high efficiency, zero emission, low temperature operation, and fast dynamic response that are widely recognized as the promising next-generation automotive propulsion ${ }^{[3-5]}$ Improving cell performance by the optimal design is critical for the future development of the PEM fuel cell. As a main component of the PEM fuel cell, the bipolar plate (BP) should simultaneously provide mechanical support of electrodes, conduct current, supply gas reactants, discharge liquid water, and dissipate heat. These functions, especially sufficient gas supply to the electrode and uniform gas distribution among the activation plane, will directly determine the PEM fuel cell performance and durability. ${ }^{[6]}$ Furthermore, cathode flow field optimization is critical due to the significance of sufficient oxygen supply of the cathode. ${ }^{[7}$ 23]

State key Laboratory of Engines, Tianjin University, 135 Yaguan

Road, Tianjin 300350, China.

*Email: kjiao@tju.edu.cn (K. Jiao)

\# equal contribution
Trogadas et al. ${ }^{[7]}$ designed a lung-inspired flow field for the cathode, namely a fractal flow field with multi-level gas distribution, to achieve uniform reactant distribution in the activation plane and minimize the entropy production. The proposed flow field plate was processed by additive manufacturing. The experimental results showed that the PEM fuel cell with the lung-inspired flow fields of three- and fourlevel distribution presented higher performance $(20 \% \sim 30 \%$ increase) and lower pressure drop (50\% 75\% decrease) than that with the conventional serpentine flow field. He et al. ${ }^{[8]}$ designed and machined a cathode three-dimensional (3D) flow field with sloping baffles. Compared with the conventional parallel flow field, the proposed flow field improved the cell performance, especially in the high current density region by enhancing oxygen supply. The effect of the inclination angle was discussed in the view of water management, and results showed that the small inclination angle was better at high water content conditions, while the large angle was better at low water content conditions. Bao et al..$^{[9]}$ numerically investigated the single- and two-phase flow characteristics of the most popular 3D flow field, 3D fine mesh flow field, that consisted of the micro and repeated 3D baffled structures. They tracked the transport phenomenon of liquid and gas 
separation through the 3D micro baffle that could effectively reduce liquid coverage on the surface of the gas diffusion layer (GDL), and therefore improved oxygen supply. Azarafza et al. ${ }^{[10]}$ compared the blocked parallel flow field and metal foamflow field for the cathode with three conventional flow fields (parallel, serpentine, and interdigitated) by conducting the PEM fuel cell computational fluid dynamics (CFD) model. The numerical results showed that the cell with the metal foam flow field had the best performance among these, that had low water saturation, uniform current and temperature distribution, and relatively medium pressure drop. They also indicated that the metal foam flow field performed well at medium and high humidity, while the interdigitated flow field would perform good at low humidity. Xing et al..$^{[1]}$ designed a parallel flow field with controllable pressure gradient across adjacent channels for the cathode. In this flow field, there existed two sets of inlets and outlets that separated the channels into two unconnected regions. Air with different pressure could be separately supplied into the channels of two regions that achieved controllable pressure gradient across adjacent channels. Its other advantage was easy to be machined. Experimental and numerical works were both conducted, and the proposed flow field could increase oxygen concentration and reduce water saturation at the under-shoulder region by the enhancement of cross-flow between adjacent channels. Wan et al. ${ }^{[12]}$ proposed a M-like channel. Different from the wave-like channel that had a series of arc-shaped blocks along the channel, the M-like channel had two arc-shaped columns in the cross-section of the channel. The M-like channel was verified by the PEM fuel cell numerical model of COMSOL, and the results showed that the maximum power density of the cell with the M-like channel increased $21.3 \%$ than that with the wave-like channel.

In our previous work, we proposed the concept of a novel dot matrix and sloping baffle flow field for the PEM fuel cell cathode, and numerically investigated the advantages of the proposed concept, while machining of the matrix flow field

(a)

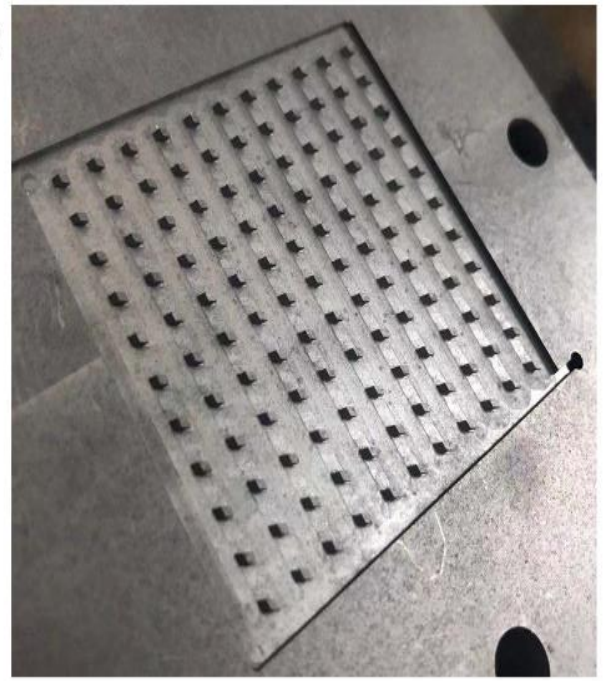

(b)
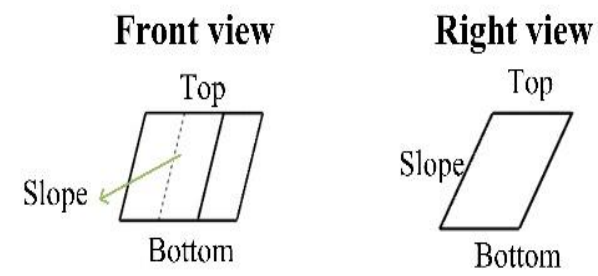

\section{Plane view}

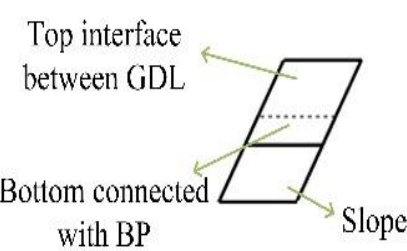

and the experimental work were absent. ${ }^{[23]}$ In this work, we design and process a series of flow field plates based on the novel matrix flow field design. We experimentally demonstrate the characteristics of the matrix flow field compared to the conventional flow fields through cell performance test, electrochemical impedance spectroscopy (EIS) technique. Furthermore, the effects of the single block area and block arrangement are discussed, and ex-situ twophase flow visualization is carried out to evaluate the water removal capacity. The relative humidity $(\mathrm{RH})$ is considered as a critical variable. The experimental results show that the current density of the cell with the matrix flow field is $75 \%$ higher than that with the conventional parallel and serpentine flow fields when $\mathrm{V}=0.6 \mathrm{~V}$ and $\mathrm{RH}=100 \%$. Meanwhile, the pressure drop of the cell with the matrix flow field is much less than that with the serpentine flow field.

\section{Experimental}

\subsection{Flow field design}

The photo of the matrix flow field plate and three views of the single block are shown in Fig. ${ }^{\left[{ }^{[23]}\right.}$ The plane view of the single block is the diamond shape, and the acute angle is $60^{\circ}$. The two acute angles point to the inlet and outlet of the flow field, respectively. The inclination angle of the block is $60^{\circ}$. In this study, six $5 \mathrm{~cm} \times 5 \mathrm{~cm}$ cathode flow field plates are designed as shown in Fig.2. The matrix flow fields in the experimental work are larger and wider than that in the previous numerical work $(12 \mathrm{~mm} \times 53 \mathrm{~mm})$. Increasing the area and width of the flow field is more challenging to evaluate the flow field design. The detailed parameters are listed in Table 1. The inlet and outlet are located at the upper left and lower right of the flow field, and all blocks are evenly distributed in the flow field. In Table 1, the first four flow fields are square array (Fig. 2(a), (b), (c), and (d)), namely the numbers of rows and columns are the same, and the naming method is "length $(\mathrm{mm})$ interval(mm)-rows". The last two flow fields are rectangular array (Fig. 2(e) and (f)), namely the numbers of rows and

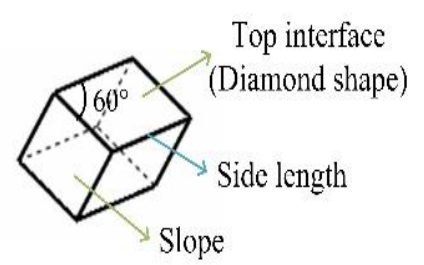

Fig. 1 Design of the dot matrix with sloping baffle flow field. (a) Photo of the flow field plate, and (b) three views of the single block, Reproduced with the permission from [23], Copyright 2019 Elsevier. 

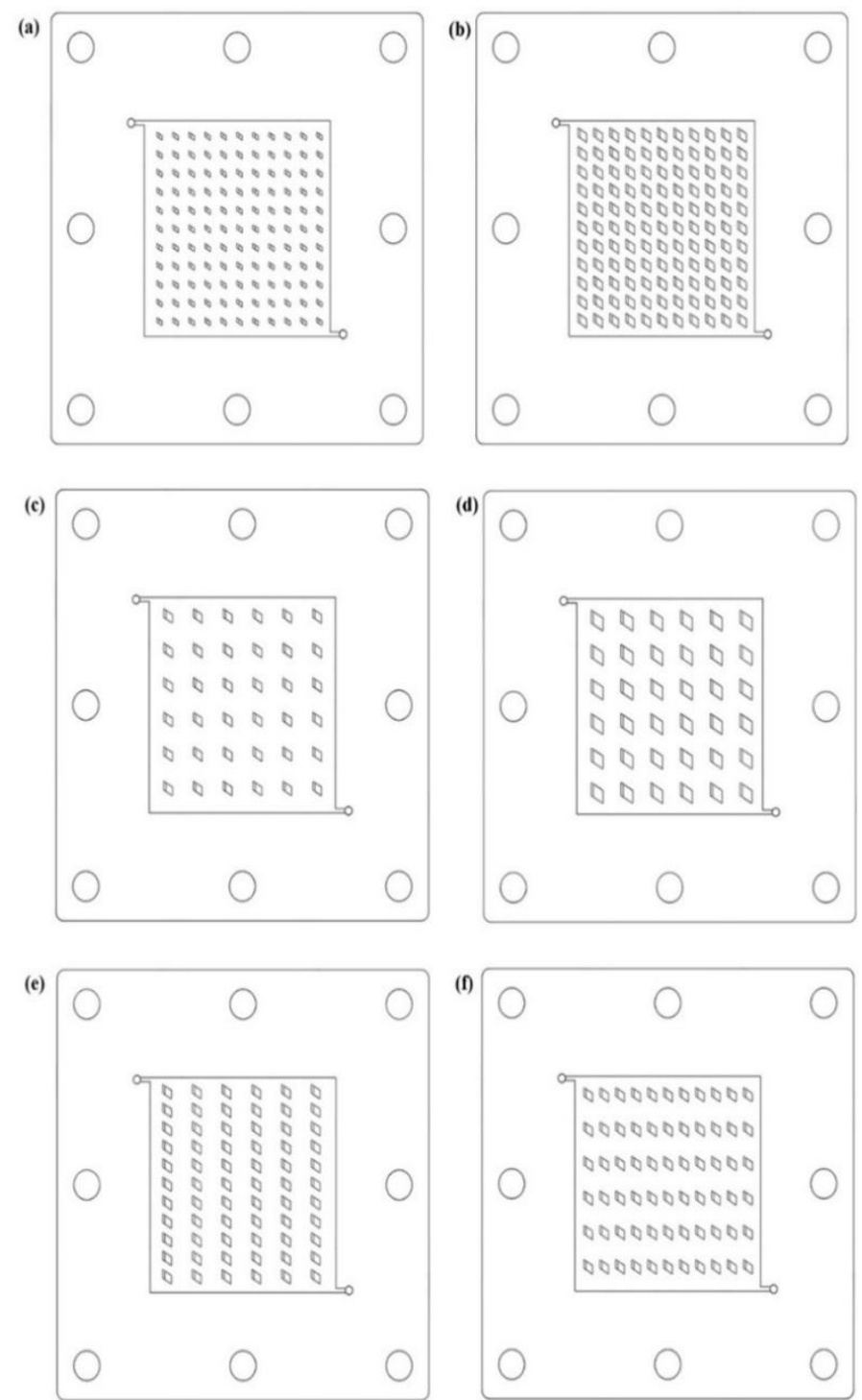

Fig. 2 Schematic of the six matrix flow fields. (a) 1-4.3-11, (b) $2-$ 4.3-11, (c) 2-8-6, (d) 3-8-6, (e) 2-11×6, and (f) 2-6×11. columns are different, and the naming method is "length(mm)rows $\times$ columns". Note that the flow field is square, so we can think that the intrinsic difference between the row and column is related to the position of the inlet and outlet (as shown in Fig. 2(e) and (f)). According to the results of our previous numerical work, the total contact area between blocks and the GDL is a critical parameter due to the relatively low contact area of the matrix flow field than that of the conventional flow field, and therefore the ratios of the contact area to activation area are also listed in Table 1.

\subsection{Experimental setup}

The assembled PEM fuel cell consists of the membrane electrode assembly (MEA), flow field plates, collector plates, and end plates (Fig. 3(a)). The MEA is a commercial product by WHUT New Energy co., Ltd. that shows stable performance in repeated experiments. The membrane is Gore and its thickness is $15 \mu \mathrm{m}$. The thicknesses and Pt loadings of the anode and cathode catalyst layer (CL) are $3.43 \mu \mathrm{m}$ and $6.87 \mu \mathrm{m}, 0.1 \mathrm{mg} \mathrm{cm}^{-2}$ and $0.4 \mathrm{mg} \mathrm{cm}^{-2}$, respectively. The GDL (carbon paper) is Toray-H-060, and its thickness is $190 \mu \mathrm{m}$. The activation area of the cell is $25 \mathrm{~cm}^{2}$. Before the cell assembly, the MEA is hot-pressed at $120^{\circ} \mathrm{C}$ and $7 \mathrm{MPa}$ for 2 minutes in advance. The flow filed plate is graphite, and processed by machining. The anode flow field is the parallel flow field. Besides the six matrix flow fields, the conventional parallel and serpentine flow fields (the width of channels and shoulders is $1 \mathrm{~mm}$ ) are also used as the cathode flow field for comparison. The schematic of the test system in this study contains a 400W PEM fuel cell test bench (Ningbo Beit, China) and electrochemical workstation (Zahner Zennium E, Germany). ${ }^{[24]}$

Table 1. Parameters of the six matrix flow field designs.

\begin{tabular}{|c|c|c|c|c|c|c|}
\hline & $\begin{array}{c}1-4.3-11 \\
\text { (baseline) }\end{array}$ & $2-4.3-11$ & $2-8-6$ & $3-8-6$ & $2-11 \times 6$ & $2-6 \times 11$ \\
\hline Block array & \multicolumn{4}{|c|}{ square array } & \multicolumn{2}{|c|}{ rectangular array } \\
\hline $\begin{array}{l}\text { Side length of the } \\
\text { single block, mm }\end{array}$ & 1 & 2 & 2 & 3 & 2 & 2 \\
\hline $\begin{array}{l}\text { Area of the single } \\
\text { block, } \mathrm{mm}^{2}\end{array}$ & 0.866 & 3.464 & 3.464 & 7.794 & 3.464 & 3.464 \\
\hline Rows & 11 & 11 & 6 & 6 & 11 & 6 \\
\hline $\begin{array}{c}\text { Interval along rows, } \\
\mathrm{mm}\end{array}$ & 4.3 & 4.3 & 8 & 8 & 4.3 & 8 \\
\hline Columns & 11 & 11 & 6 & 6 & 6 & 11 \\
\hline $\begin{array}{l}\text { Interval along } \\
\text { columns, } \mathrm{mm}\end{array}$ & 4.3 & 4.3 & 8 & 8 & 8 & 4.3 \\
\hline $\begin{array}{c}\text { Total number of } \\
\text { blocks }\end{array}$ & 121 & 121 & 36 & 36 & 48 & 48 \\
\hline $\begin{array}{l}\text { Total contact area } \\
\text { between blocks and } \\
\text { GDL, } \mathrm{mm}^{2}\end{array}$ & 104.79 & 419.14 & 124.70 & 280.58 & 166.27 & 166.27 \\
\hline $\begin{array}{l}\text { Ratio of contact area } \\
\text { to activation area }\end{array}$ & $4.19 \%$ & $16.76 \%$ & $4.99 \%$ & $11.22 \%$ & $6.65 \%$ & $6.65 \%$ \\
\hline
\end{tabular}




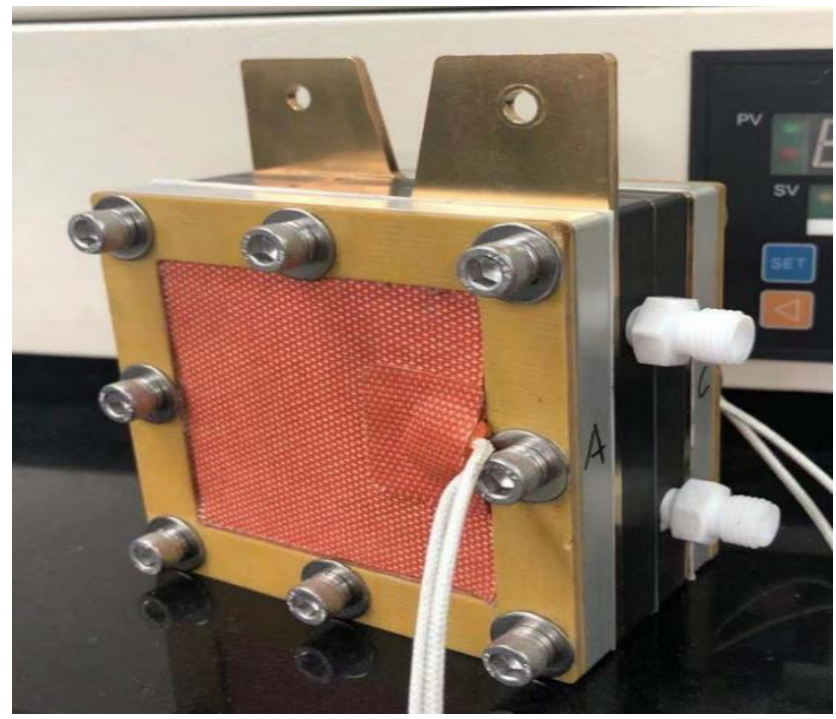

Fig. 3 Photo of the assembled PEM fuel cell.

\subsection{Test procedure}

The MEA must be activated firstly before the formal test. In the activation process, full humidified hydrogen and air are supplied to the cell and the cell works in various currents for around six hours. For the formal test, the cell temperature is constant as $70{ }^{\circ} \mathrm{C}$. The hydrogen and air supply rates are 0.5 and 1.5 SLPM, respectively, and the back pressure is 1 bar (absolute pressure). Inlet gas of various RH is supplied by controlling the dew point temperature. Before the $\mathrm{RH}$ change, the cell should be fully purged for around 30 minutes. The pressure drop of the flow field is recorded and the sample frequency is $1 \mathrm{~Hz}$. EIS is carried out in the constant current mode by the electrochemical workstation. Sinusoidal current disturbance is adopted, and the amplitude of current disturbance is $10 \%$ of the real-time current to stabilize the voltage. The frequency range is $100 \mathrm{kHz} \sim 0.1 \mathrm{~Hz}$.

\subsection{Visualization}

The two-phase flow performance is a critical factor to evaluate a flow field design. ${ }^{[25-28]}$ The ex-situ liquid water removal process of the matrix flow field is observed by the high-speed camera to evaluate the liquid discharge capacity. The plate lies flat and the flow field faces up. The transparent acrylic plate covers the flow field, and a $1 \mathrm{~mm}$-diameter hole for water injection is located near the inlet of the flow field. We use a syringe to fill the flow field with liquid water, and block the

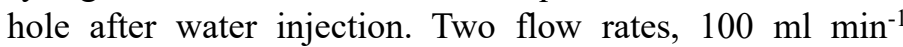
(velocity is around $2.1 \mathrm{~m} \mathrm{~s}^{-1}$ ) and $600 \mathrm{ml} \mathrm{min}{ }^{-1}$ (velocity is around $12.7 \mathrm{~m} \mathrm{~s}^{-1}$ ), of air are supplied from the inlet of the flow field, and the water removal process is recorded by the highspeed camera (Photron fastcam sa1.1, Japan). The images are output at the interval of $300 \mathrm{~ms}$ until the water distribution no longer changes by air flow.

\section{Results and discussion \\ 3.1 Compared with conventional flow fields}

In this section, 1-4.3-11 is chosen as the baseline of the matrix flow field and compared with the conventional flow fields. Fig. 4(a) shows the polarization curves of the cells with the matrix (1-4.3-11), parallel, and serpentine flow field at $\mathrm{RH}=40 \%$, $60 \%, 80 \%$, and $100 \%$. The errors of the polarization curves are generally lower than $0.01 \mathrm{~V}$, therefore the error bars are neglected in the following figures. The performance of cells with the tradition flow fields is evaluated with that in the literature, and the performance is in the comparable level. ${ }^{[29,30]}$ The cell with the parallel flow field shows the worst performance, and the obvious water flooding occurs when the current density is above around $0.6 \mathrm{~A} \mathrm{~cm}^{-2}$. At most humidity conditions $(60 \%, 80 \%$, and $100 \%)$, the cell with $1-4.3-11$ shows better performance than that with the serpentine flow field. However, the situation is opposite at $\mathrm{RH}=40 \%$ that will be further discussed combined with the EIS results. Also note that the obvious water flooding occurs when the current density is above around $1.1 \mathrm{~A} \mathrm{~cm}^{-2}$ for 1-4.3-11, and the voltage drops quickly. Furthermore, the polarization curve of the cell with the matrix flow field in this work is compared to that with analogous flow fields in the previous literature. ${ }^{[31,32]}$ Wen et al. ${ }^{[31]}$ proposed a intersectant flow field design, and the experimentally measured current densities of the cell with the intersectant flow field were around $0.36 \mathrm{~A} \mathrm{~cm}^{-2}$ at $0.6 \mathrm{~V}$, and $0.73 \mathrm{~A} \mathrm{~cm}^{-2}$ at $0.4 \mathrm{~V}(\mathrm{RH}=100 \%)$. Atyabi et al. ${ }^{[32]}$ proposed a honeycomb flow field design, and the predicted current densities of the cell with the honeycomb flow field by simulation were around $0.51 \mathrm{~A} \mathrm{~cm}^{-2}$ at $0.6 \mathrm{~V}$, and $0.85 \mathrm{~A} \mathrm{~cm}^{-2}$ at $0.4 \mathrm{~V}(\mathrm{RH}=100 \%)$. In this work, the current densities of the cell with the matrix flow field are $0.7 \mathrm{~A} \mathrm{~cm}^{-2}$ at $0.6 \mathrm{~V}$, and 1.23 $\mathrm{A} \mathrm{cm}^{-2}$ at $0.4 \mathrm{~V}(\mathrm{RH}=100 \%)$ which are much better than that in the previous literature. Although there still exist other factors that will influence the cell performance, such as difference between MEAs and difference between experimental and numerical works, this comparison could demonstrate that the matrix flow field is an advantageous design. 


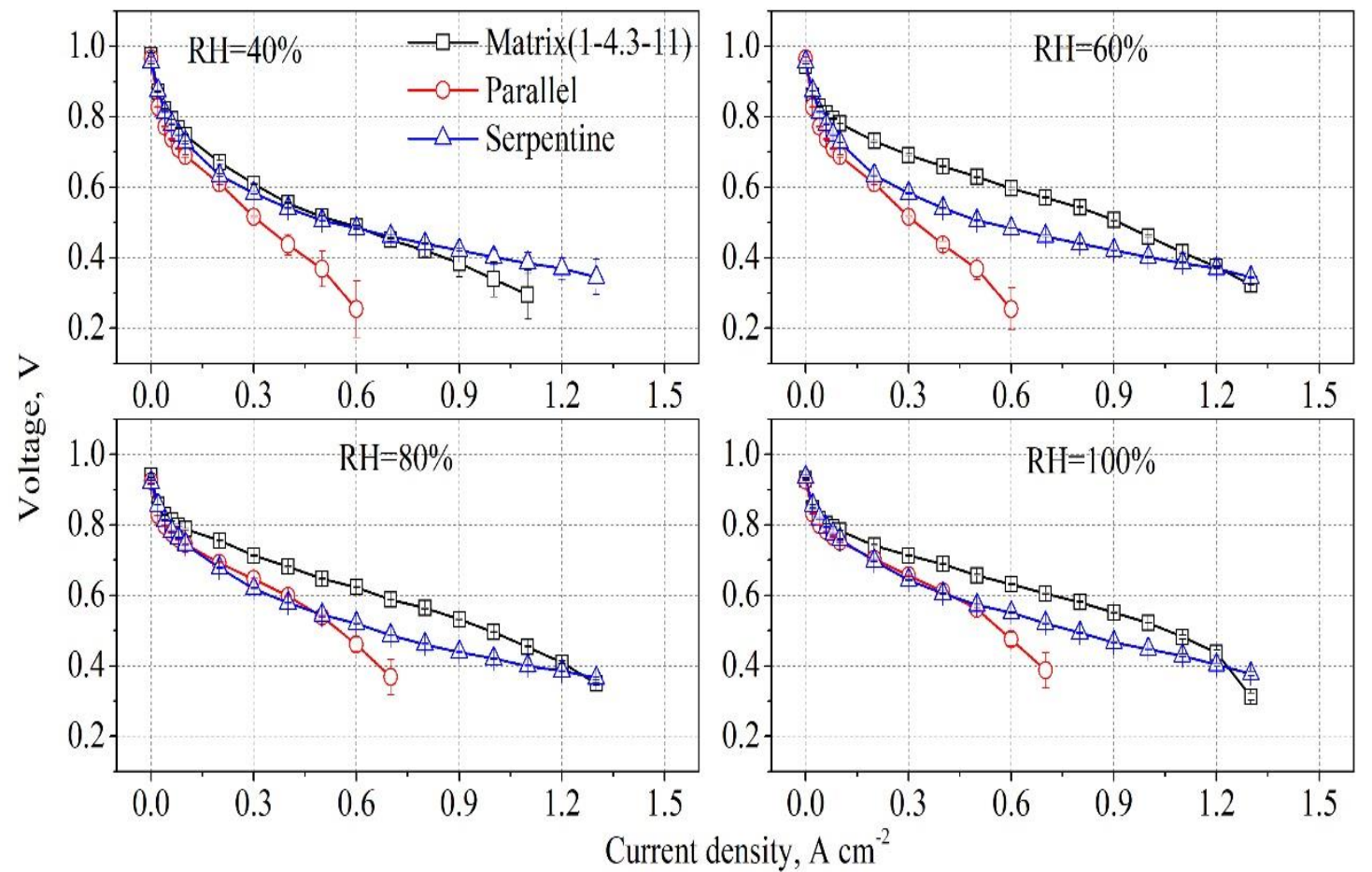

(a)

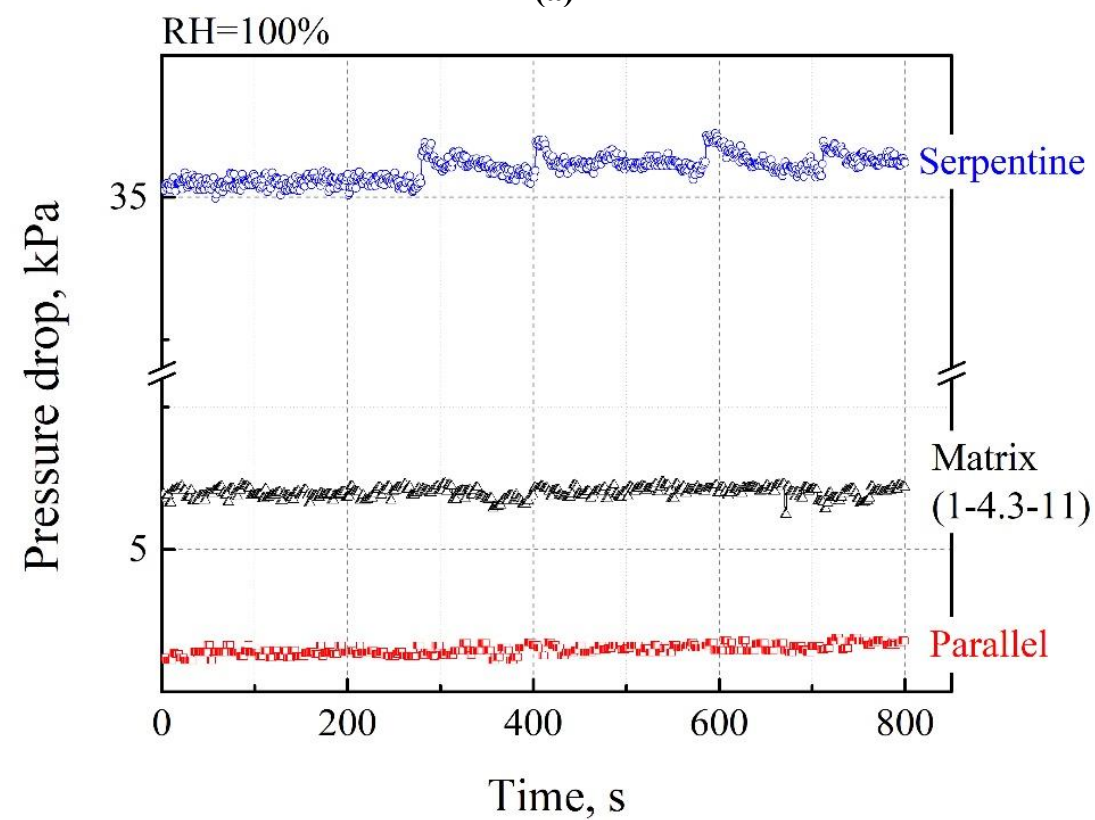

(b)

Fig. 4 Comparison of the matrix flow field and conventional flow fields. (a) Polarization curves at RH=40\%, 60\%,80\%, and 100\%, and (b) pressure drop at $\mathrm{RH}=100 \%$ of the cells with the matrix (1-4.3-11), parallel, and serpentine flow field.

As shown in Fig. 4(b), the pressure drop of 1-4.3-11, the parallel flow field, and serpentine flow field at $\mathrm{RH}=100 \%$ is around $6 \mathrm{kPa}, 3.2 \mathrm{kPa}$, and $35 \mathrm{kPa}$, respectively. The pressure drop of 1-4.3-11 is higher than that of the parallel flow field, but much lower than that of the serpentine flow field. Combining the polarization curves, 1-4.3-11 can improve the cell voltage with relatively low pressure drop, namely low pump loss, but its liquid discharge capacity is worse than the serpentine flow field.

Due to the fact that the parallel flow field is not competitive with 1-4.3-11 and the serpentine flow field, only 1-4.3-11 and the serpentine flow field are analyzed for the EIS results. Fig. 5 shows the EIS results of the cells with the two flow fields at $\mathrm{RH}=40 \%, 60 \%, 80 \%$, and $100 \%$, and current densities of $0.4 \mathrm{~A}$ $\mathrm{cm}^{-2}$ and $0.8 \mathrm{~A} \mathrm{~cm}^{-2}$. The ohmic resistance of $1-4.3-11$ is obviously larger than that of the serpentine flow field in any case because the small contact area for current conduction of $1-4.3-11$. The contact ratio of $1-4.3-11$ is only $4.19 \%$ which is greatly less than that of the serpentine flow field (around 50\%). With increasing RH (from $40 \%$ to $100 \%$ ), the activation and ohmic losses of the cell with 1-4.3-11 are significantly reducing, while that with the serpentine flow field does not 

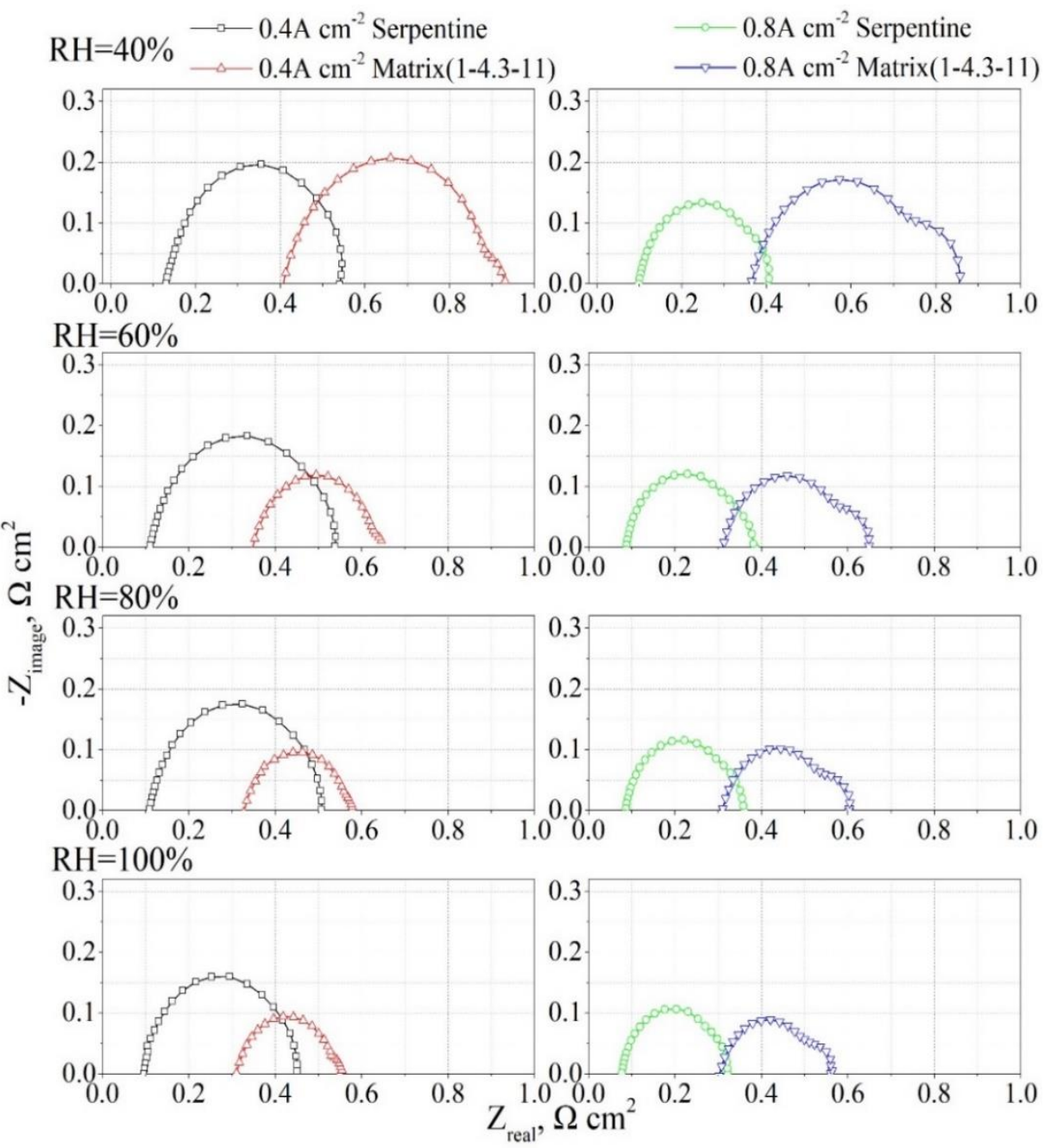

Fig. 5 Comparison of the matrix flow field and conventional flow fields. EIS results of the cells with the matrix (1-4.3-11) and serpentine flow field at $\mathrm{RH}=40 \%, 60 \%, 80 \%$, and $100 \%$, and the current density of $0.4 \mathrm{~A} \mathrm{~cm}^{-2}$ and $0.8 \mathrm{~A} \mathrm{~cm}^{-2}$.

change much. This indicates that the matrix flow field is more sensitive to humidity conditions than the serpentine flow field. The matrix flow field has the larger fluid domain for gas supply to the electrode than the serpentine flow field, and therefore more humidified gas would increase the water content of the membrane, improve proton conductivity, and increase the electrochemical reaction rate at high humidity supply. On the contrary, the relatively dry gas would take away water of the cell at low humidity supply. The activation loss of the cell with 1-4.3-11 is almost the same as that with the serpentine flow field at $\mathrm{RH}=40 \%$. While the activation loss of the cell with 1-4.3-11 is significantly less than that with the serpentine flow field at $\mathrm{RH}=60 \%$ or higher that well accords with the polarization curves. Some level of concentration loss of the cell with 1-4.3-11 occurs at the current density of $0.8 \mathrm{~A}$ $\mathrm{cm}^{-2}$, even at low inlet $\mathrm{RH}$, that also indicates that the relatively poor liquid discharge

\subsection{Effect of the single block area}

To investigate the effect of the single block area, two groups of matrix flow fields with different single block areas and the same block arrangement are compared and analyzed. Fig. 6(a) shows the polarization curves of the cells with 1-4.3-11, 2-4.3$11,2-8-6$, and 3-8-6 at different RH. Firstly, the comparison between 1-4.3-11 and 2-4.3-11 shows that the cell performance with 2-4.3-11 is better than that with 1-4.3-11 at $\mathrm{RH}=40 \%$, but that with $1-4.3-11$ is better at $\mathrm{RH}=60 \%$ or higher. Similarly, the cell performance with 3-8-6 is similar as that with 2-8-6 at relatively low $\mathrm{RH}(40 \%, 60 \%$, and $80 \%)$, but that with 2-8-6 is obviously better at high RH (100\%). In summary, the matrix flow field with the large single block area is better at low RH, while that with the small block area is better as increasing RH. Therefore, the matrix flow field with the small single block area has more remarkable characteristics of the matrix flow field than that with the large single block area. We can infer that refined machining, namely decreasing the scale of the single block is helpful to increase the performance and reinforce the advantages of the matrix flow field. It can be also found that the cell performance difference between 2-8-6 and 3-8-6 is weaker than that between 1-4.3-11 and 2-4.3-11. Because the single block area of 2-4.3-11 is four times that of $1-4.3-11$, while the single block area of 3-8-6 is only 2.25 time 

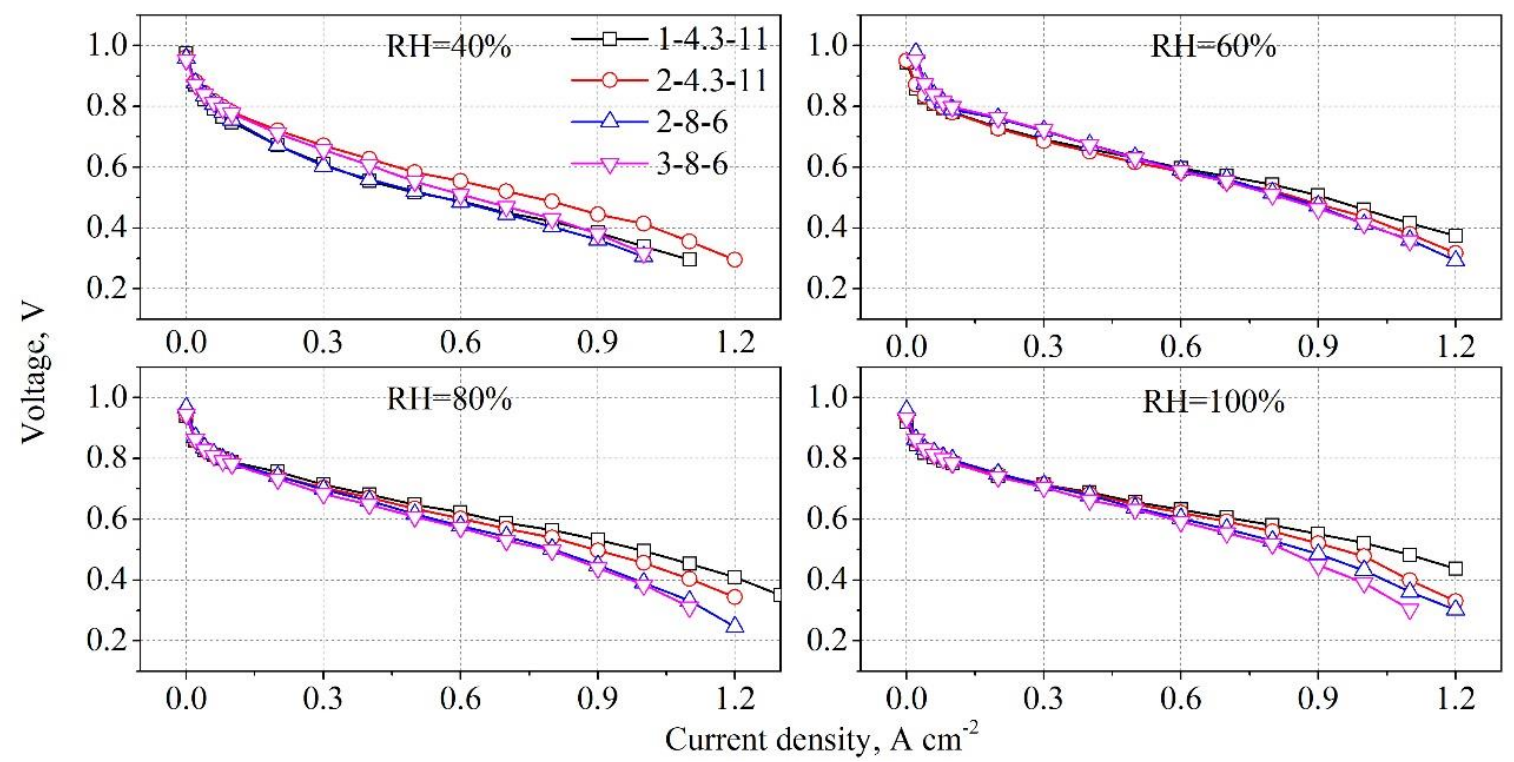

(a)

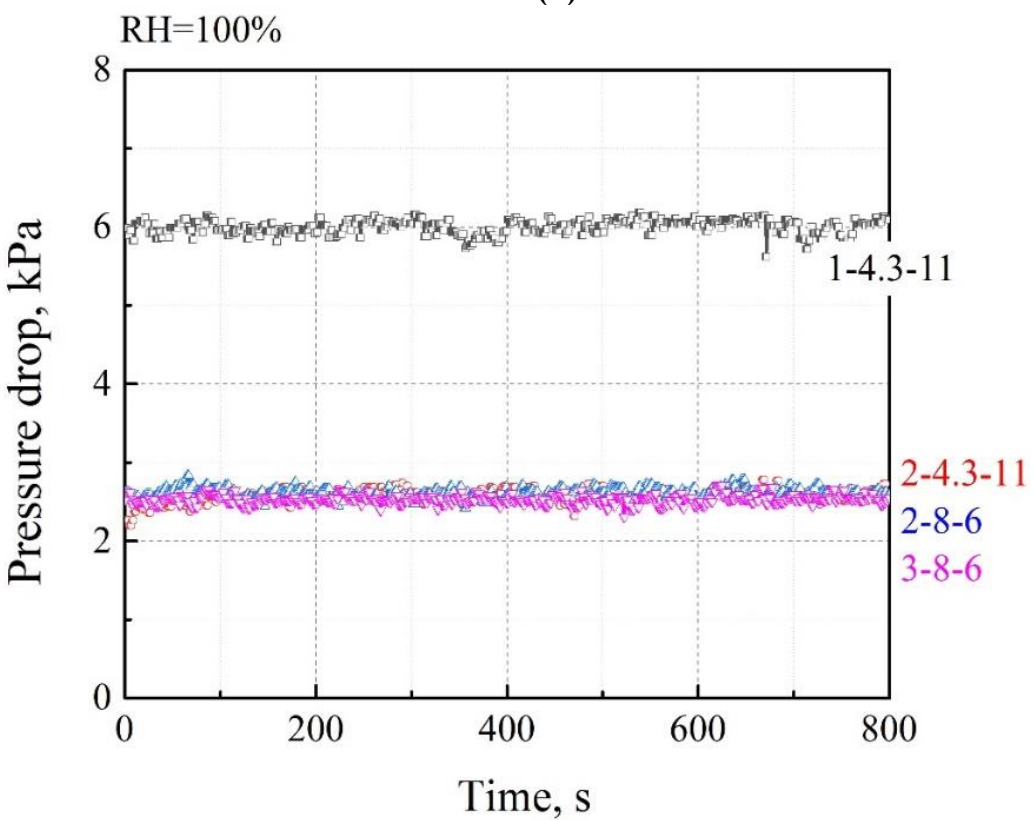

(b)

Fig. 6 Comparison of different single block areas. (a) Polarization curves at $\mathrm{RH}=40 \%, 60 \%, 80 \%$, and $100 \%$, and (b) pressure drop at $\mathrm{RH}=100 \%$ of the cells with $1-4.3-11,2-4.3-11,2-8-6$, and $3-8-6$.

that of 2-8-6. The obvious liquid flooding occurs in the cells capacity of 1-4.3-11 than that of the serpentine flow field. with the four matrix flow fields at $\mathrm{RH}=100 \%$ and the current density of $1.2 \mathrm{~A} \mathrm{~cm}^{-2}$, and therefore we can infer that the matrix flow field cannot efficiently discharge liquid water at high relative humidity and high current density. As shown in Fig.6(b), the pressure drop of 1-4.3-11 is around $6 \mathrm{kPa}$, and that of the others is around $2 \mathrm{kPa}$. It can be found that the small single block area would increase pressure drop when blocks arrange compactly (like 1-4.3-11 and 2-4.3-11), while the single block area would not obviously influence pressure drop when blocks arrange sparsely (such as 2-8-6 and 3-8-6).

As shown in Fig. 7(a) and (b), the EIS results of the cells with 1-4.3-11 and 2-4.3-11, and 2-8-6 and 3-8-6 further prove the above analysis. The ohmic loss of the cell with 1-4.3-11 is larger than that with 2-4.3-11, while the activation loss of the cell with 1-4.3-11 is smaller than that with 2-4.3-11 at $\mathrm{RH}=60 \%$ or higher. But this difference becomes weak between the cells with 2-8-6 and 3-8-6. In the experimental range, the matrix flow field with the small single block area causes the large ohmic loss, but the small activation loss at relatively high humidity conditions. Furthermore, the concentration loss of the cell with 1-4.3-11 is more obvious than that with 2-4.3-11 that indicates that 2-4.3-11 has better liquid discharge capacity than 1-4.3-11. While the concentration loss of the cells with 28-6 and 3-8-6 is much similar. Therefore, the effect of the single block area generally becomes weak when the block area is relatively large. 


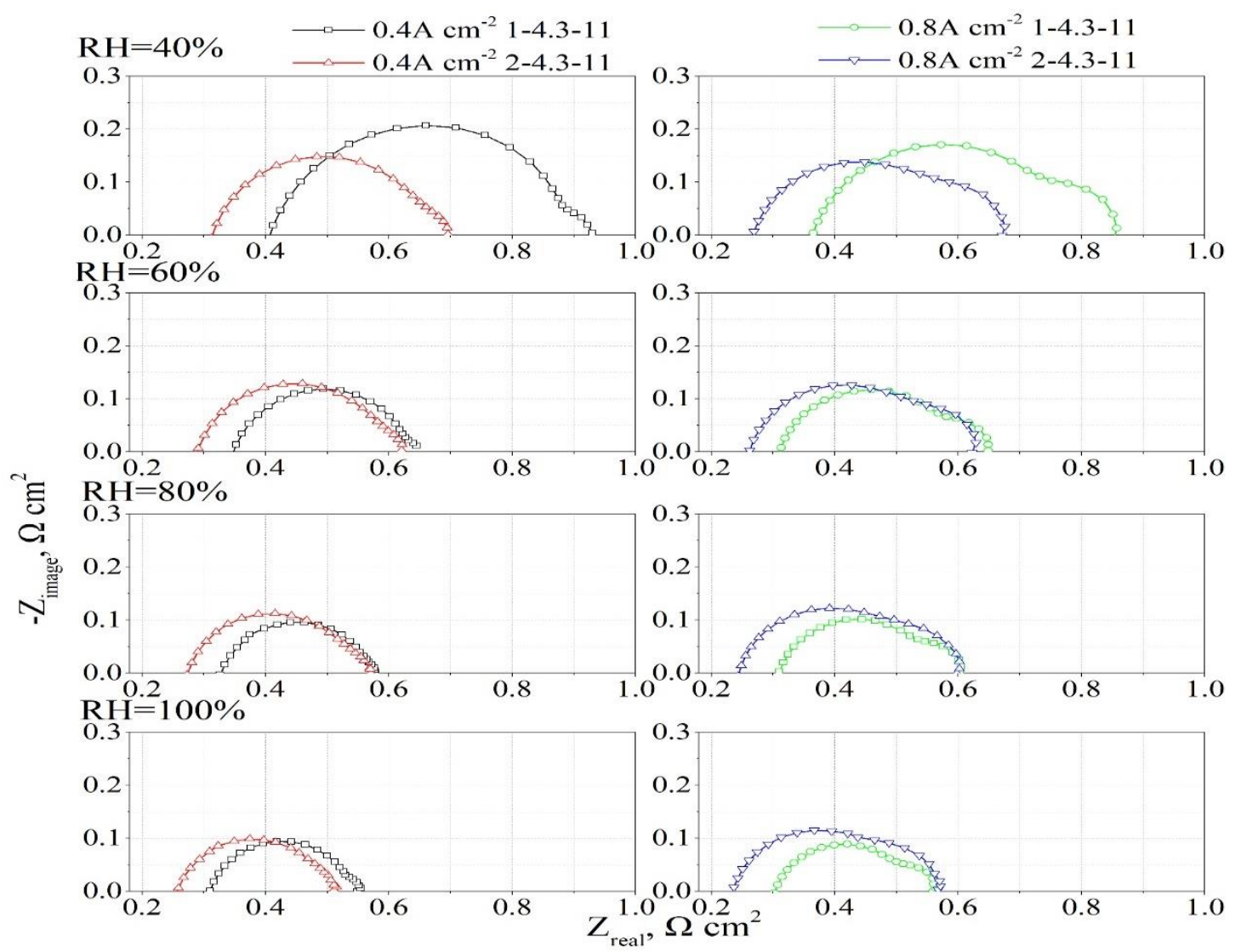

(a)

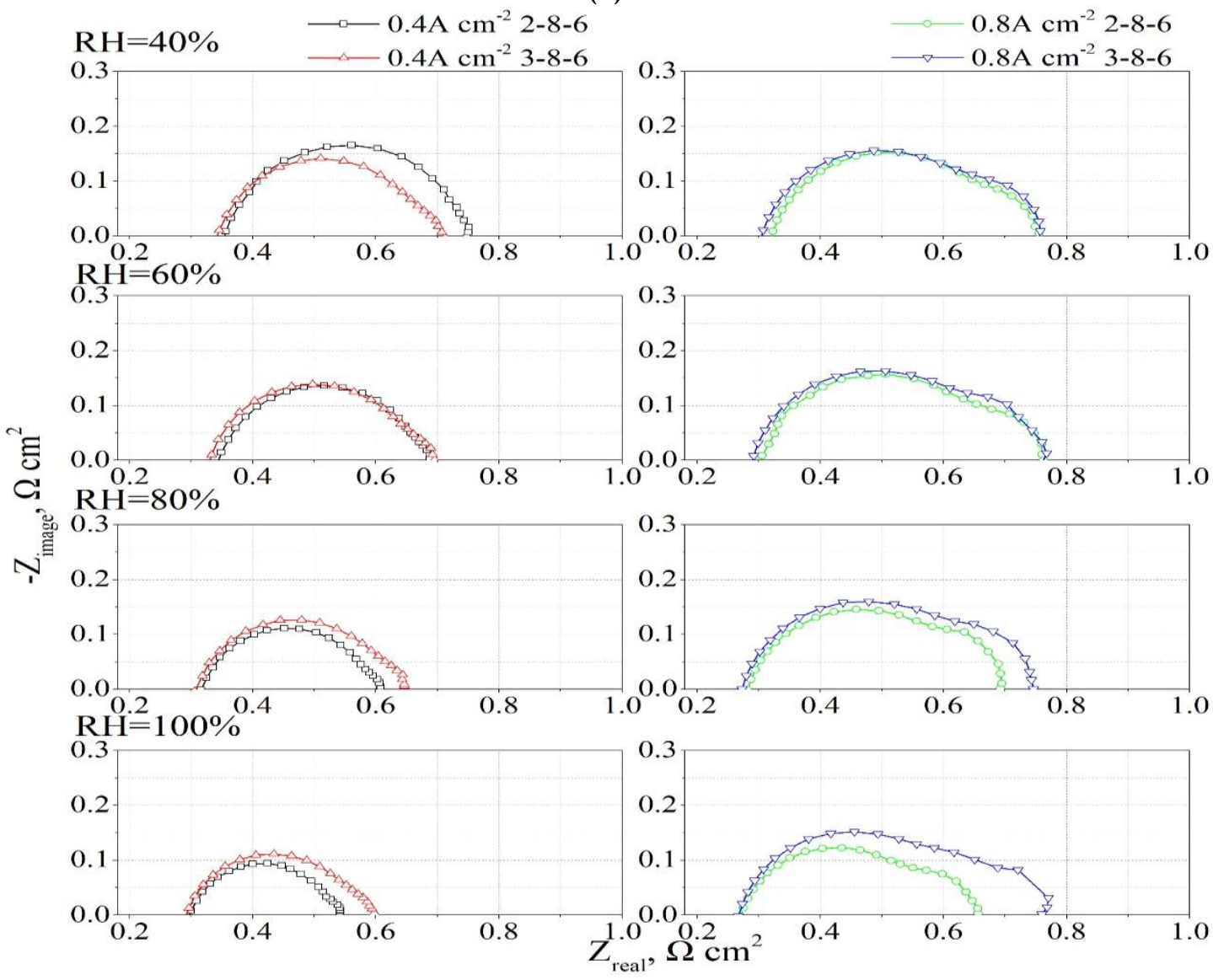

(b)

Fig. 7 Comparison of different single block areas. EIS results of the cells with (a) 1-4.3-11 and 2-4.3-11, and (b) 2-8-6 and 3-8-6 at $\mathrm{RH}=40 \%, 60 \%, 80 \%$, and $100 \%$, and the current density of $0.4 \mathrm{~A} \mathrm{~cm}^{-2}$ and $0.8 \mathrm{~A} \mathrm{~cm}^{-2}$. 
(a)

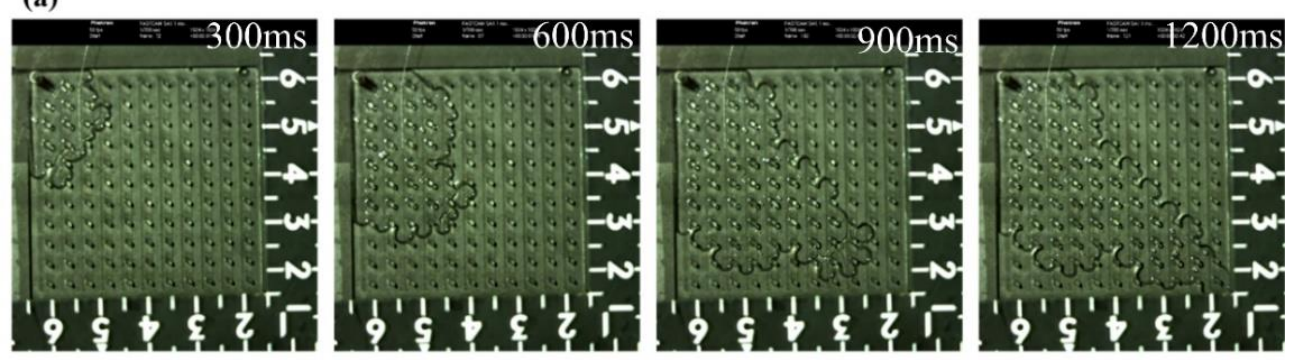

(b)

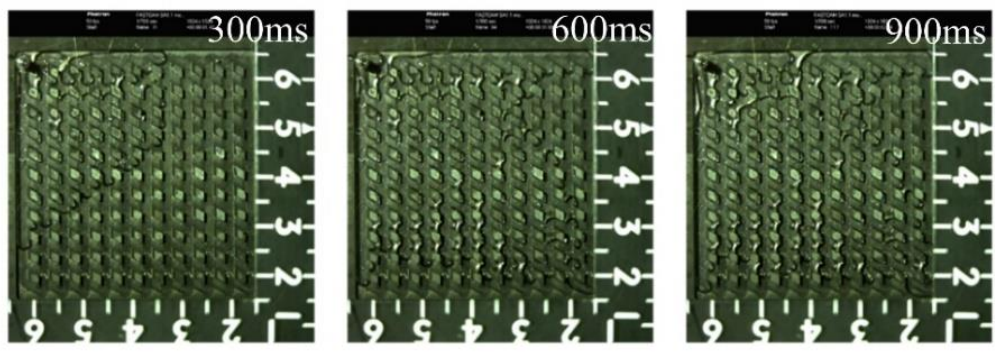

(c)

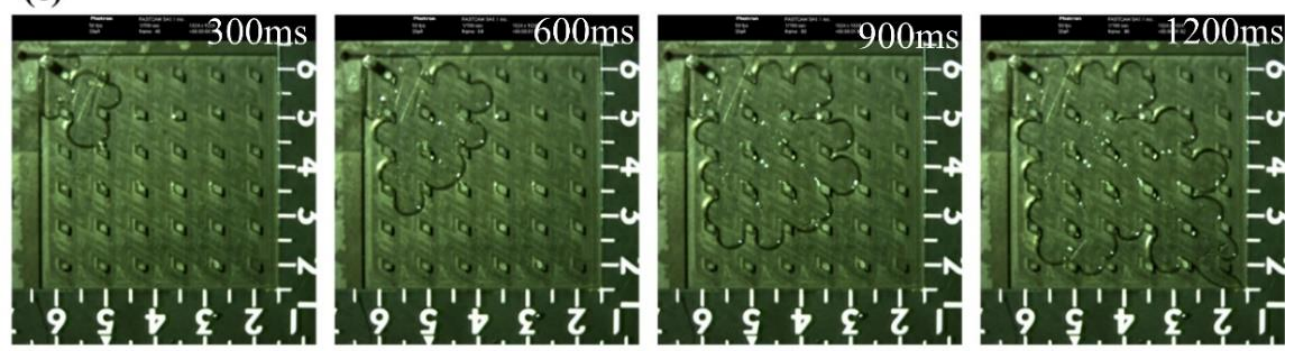

(d)

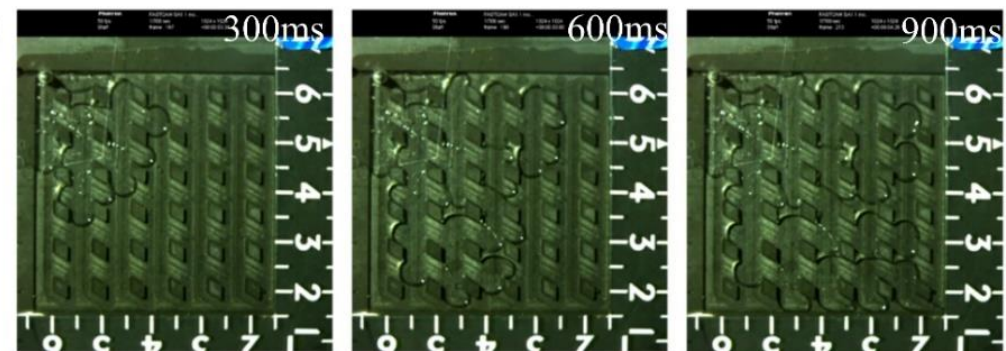

Fig. 8 Comparison of different single block areas. Visualized water discharge process of (a) 1-4.3-11, (b) 2-4.3-11, (c) 2-8-6, and (d) 3-8-6 at the low air supply rate $\left(2.1 \mathrm{~m} \mathrm{~s}^{-1}\right)$.

The visualized water discharge processes of 1-4.3-11, 2- also effective for 2-8-6 and 3-8-6 that less liquid exists in 3-84.3-11, 2-8-6, and 3-8-6 at the low air supply rate $\left(2.1 \mathrm{~m} \mathrm{~s}^{-1}\right) 6$ than that in 2-8-6. But it should be noted that although are shown in Fig. 8. Note that since the flow field is fully increasing the single block can mitigate the liquid flooded, this process cannot fully reflect the liquid water distribution of an operating PEM fuel cell. And the graphite flow field is hydrophilic surface, while the GDL is hydrophobic surface. The removal of emerged water on the GDL surface should be easier than the water removal on the surface of the flow field. Comparing the images of 1-4.3-11 and 2-4.3-11, there only exists a little water inside 2-4.3-11 after purge $(900 \mathrm{~ms})$, while a large amount of water still cannot be discharged by air flow at the upper right of 1-4.3-11 after $1200 \mathrm{~ms}$. Air flow is mainly along the diagonal line from the inlet to the outlet for 1-4.3-11. This is because the limited air guidance effect of the small side length along the side of the flow field. With the side length of the single block increasing to $2 \mathrm{~mm}$, the air guidance effect is improved that is helpful to air flow distribution and liquid discharge. The phenomenon is accumulation at the corners of the flow field, it also leads to some level of liquid retention at the surrounding areas of blocks. Furthermore, we want to figure out whether increasing air flow rate could improve liquid discharge of the matrix flow field. Surprisingly, as shown in Fig. 9, increasing the air flow rate even leads to more liquid accumulation at the corners of the flow field for 1-4.3-11 and 2-8-6. The flow directly moves along the diagonal line from the inlet to the outlet, and the effect of flow guidance becomes weak even at high speed flow. Therefore, only increasing the flow rate cannot effectively improve liquid discharge of the matrix flow field. If the matrix flow field wants to apply in the full scale commercial automotive fuel cells with the activation area of 200 to 300 $\mathrm{cm}^{2}$, creating sub-regions and compulsive gas distribution should be considered. 
(a)
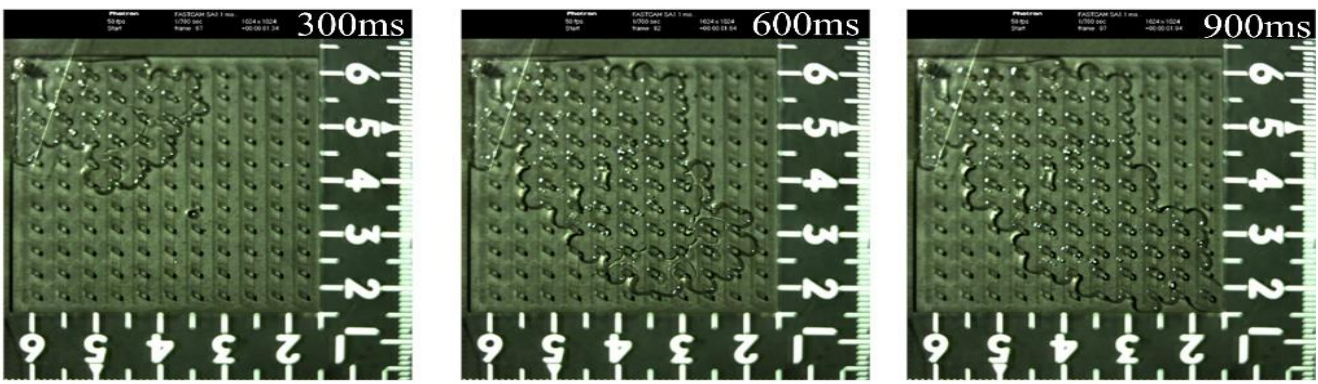

(b)
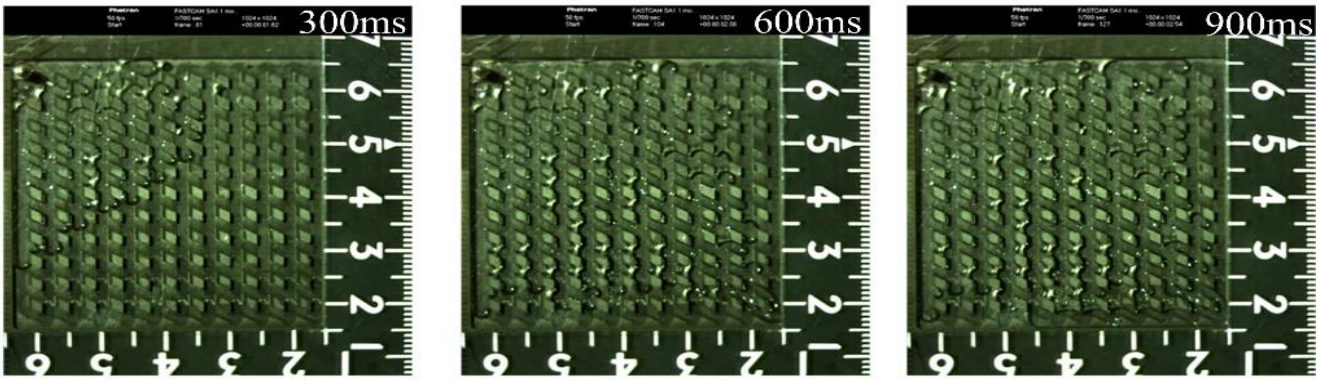

(c)
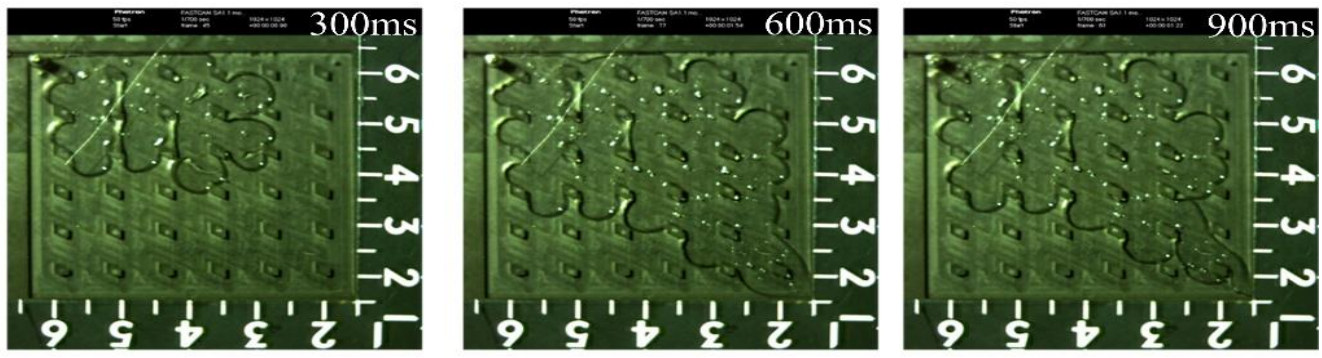

(d)
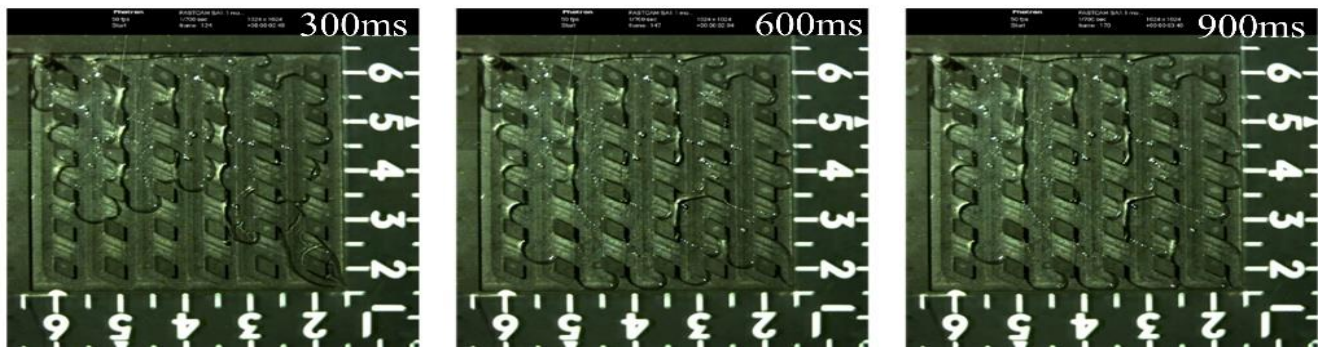

Fig. 9 Comparison of different single block areas. Visualized water discharge process of (a) 1-4.3-11, (b) 2-4.3-11, (c) 2-8-6, and (d) 3-8-6 at the high air supply rate $(12.7 \mathrm{~m} \mathrm{~s}-1)$.

\subsection{Effect of the block arrangement}

In this section, the matrix flow fields with different block arrangements, including square array and rectangular array, and the same single block area are analyzed and discussed. Fig. 10(a) shows the polarization curves of the cell with 2-4.3-11, $2-8-6,2-11 \times 6$, and $2-6 \times 11$ at $\mathrm{RH}=100 \%$. The cell with the most compact block arrangement flow field, 2-4.3-11, has the best performance, and then that with $2-11 \times 6$ is the second, and that with 2-8-6 and 2-6×11 are similar and the worst among these. Generally, with the same single block area, the flow field with a compacter block arrangement, or more block numbers would show better performance. Considering the obvious performance difference between the cells with $2-11 \times 6$ and $2-6 \times 11$, the numbers of rows and columns also influence the performance of the matrix flow field with rectangular array. The liquid flooding occurs for $2-6 \times 11$ at the current density of around $1 \mathrm{~A} \mathrm{~cm}^{-2}$, while $2-11 \times 6$ and 2-6×11 has the same block number. We infer that the performance difference of $2-11 \times 6$ and $2-6 \times 11$ is caused by their difference of liquid discharge capacity. Fig. 10(b) shows the pressure drop of the four matrix flow fields that is around $2 \mathrm{kPa}$. It further proves that the pressure drop of the matrix flow field is very low compared to the serpentine flow field, and the block arrangement will not obviously influence pressure drop.

Fig. 11(a) shows the EIS results of the cell with 2-4.3-11 and 2-8-6. The ohmic and activation losses of the cell with 24.3-11 are both less than that with 2-8-6. On the one hand, the contact area of 2-4.3-11 is larger than that of 2-8-6 that is helpful to current conduction. On the other hand, it demonstrates that the oxygen supply and gas distribution characteristics of 2-4.3-11 are also better than that of 2-8-6. Fig. 11(b) shows the EIS results of the cell with $2-11 \times 6$ and 2$6 \times 11$. Although the contact areas of $2-11 \times 6$ and $2-6 \times 11$ are the same, the ohmic losses are still different caused by different 


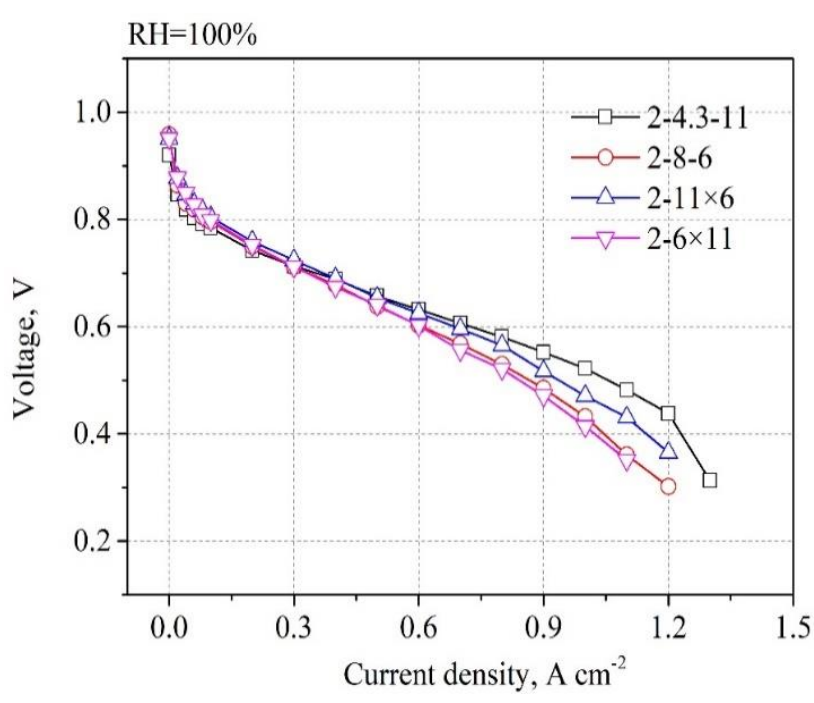

(a)

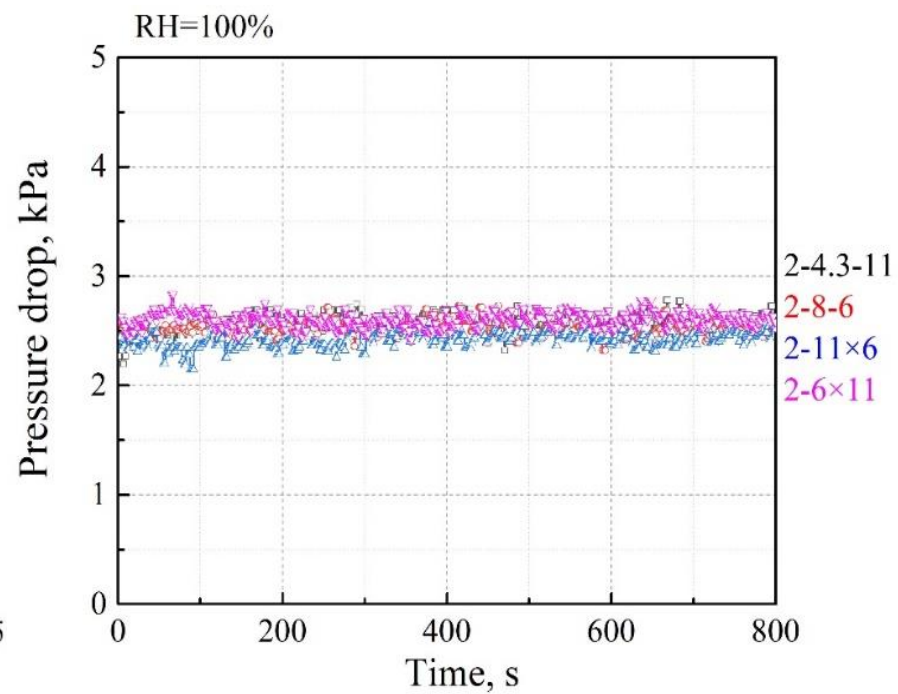

(b)

Fig. 10 Comparison of different block arrangements. (a) Polarization curves, and (b) pressure drop of the cells with 2-4.3-11, 2-8-6, $2-11 \times 6$, and $2-6 \times 11$ at $\mathrm{RH}=100 \%$.

water content and proton conductivity. Furthermore, 2-4.3-11 the matrix flow fields with rectangular array, air flow will and $2-11 \times 6$ have the same rows, and $2-4.3-11$ has more columns than $2-11 \times 6$. In the EIS results, the ohmic loss of the cell with 2-4.3-11 is less than that with $2-11 \times 6$, because $2-4.3$ 11 has the larger contact area. The activation losses of the cells with 2-4.3-11 and 2-11×6 are generally similar.

For liquid discharge, firstly we compare 2-4.3-11 and 2-86 in Fig. 8 and Fig. 9(b) and (c). Obviously, less water exists in 2-4.3-11 than that in 2-8-6 because the compacter block arrangement leads to the better air guidance effect to discharge water. Fig. 12 shows the visualized water discharge process of firstly move along the side with the small interval, namely along the rows for $2-11 \times 6$, but along the columns for $2-6 \times 11$, and then move along the other side. Less water exists in 2$11 \times 6$ than that in $2-6 \times 11$ because the flow direction of inlet gas is along the columns (as shown in Fig. 2(e) and (f)), and the effect of air guidance along the rows is more critical for gas distribution and liquid discharge.

\section{Conclusion}

$2-11 \times 6$ and $2-6 \times 11$ at the low air supply rate $\left(2.1 \mathrm{~m} \mathrm{~s}^{-1}\right)$. For field plates based on our previously proposed concept of the

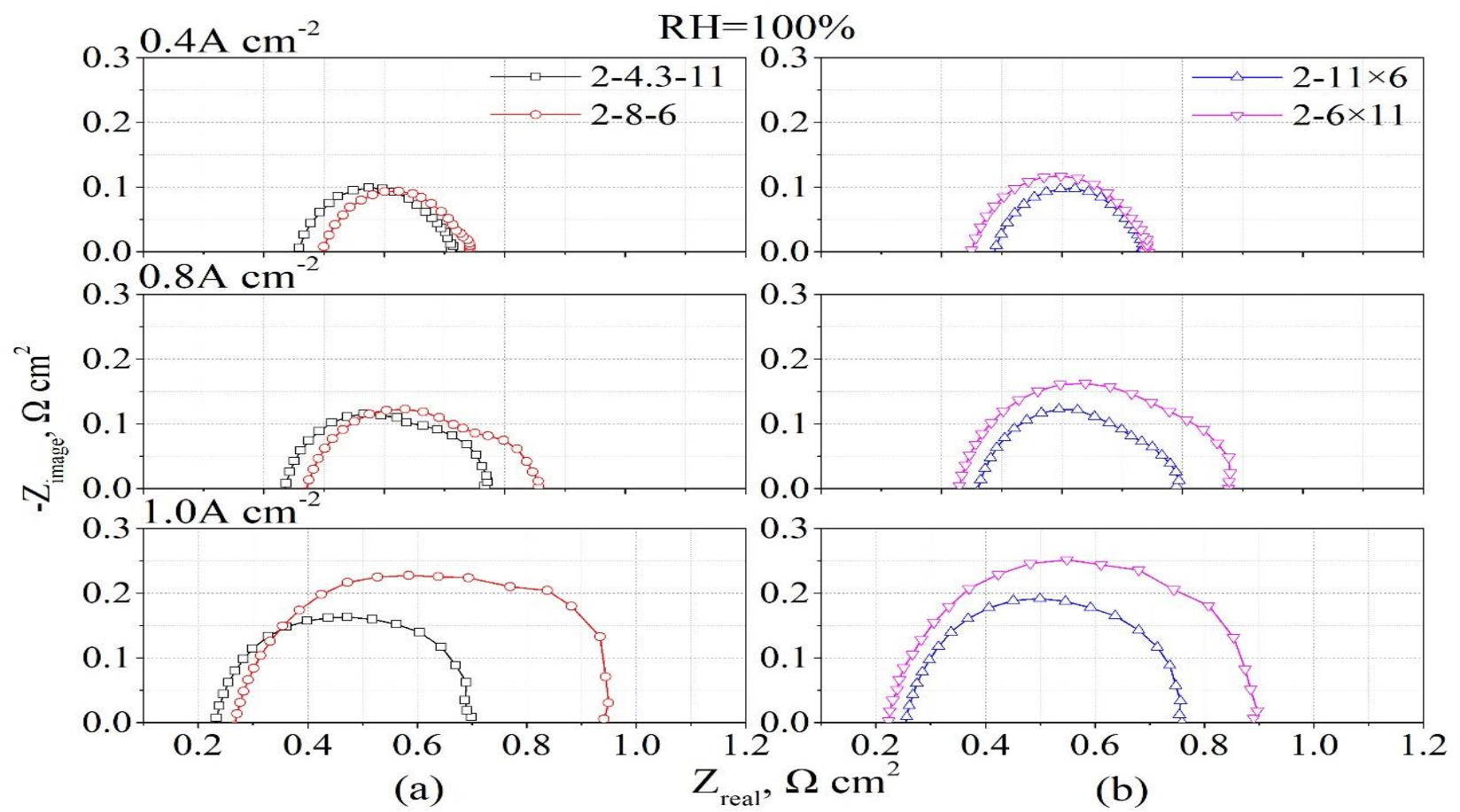

Fig. 11 Comparison of different block arrangements. EIS results of the cells with (a) 2-4.3-11 and 2-8-6, and (b) 2-11 $\times 6$ and 2-6×11 at $\mathrm{RH}=100 \%$, and the current density of $0.4 \mathrm{~A} \mathrm{~cm}^{-2}, 0.8 \mathrm{~A} \mathrm{~cm}^{-2}$, and $1.0 \mathrm{~A} \mathrm{~cm}$. 
(a)

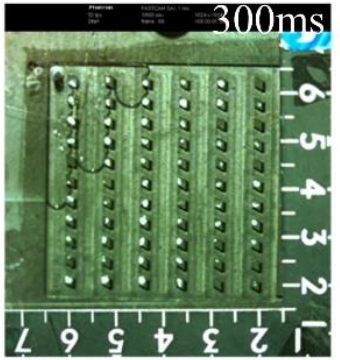

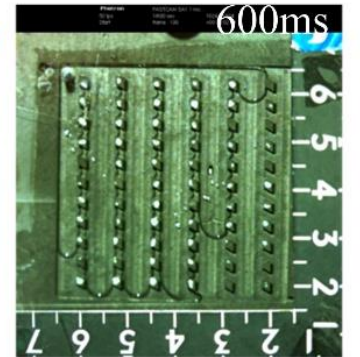

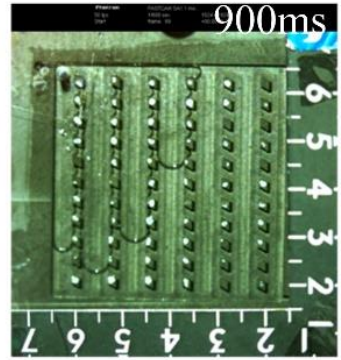

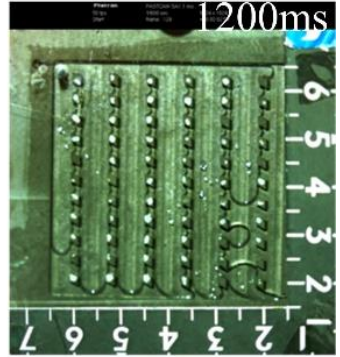

(b)
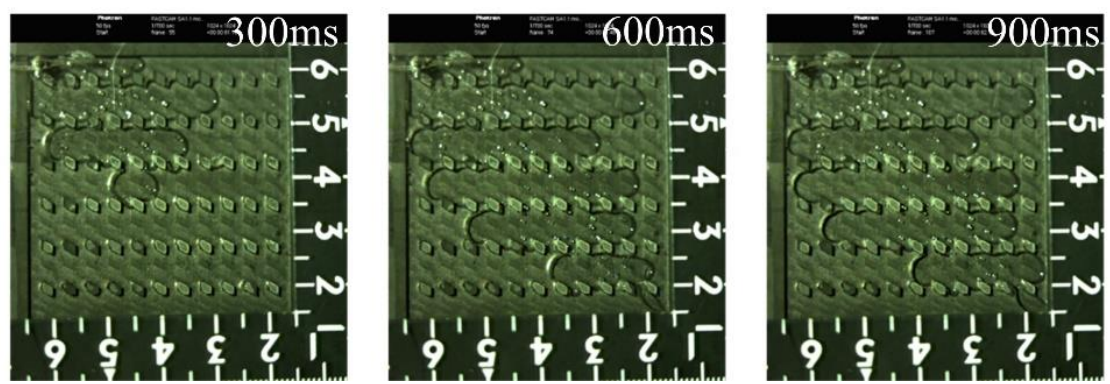

Fig. 12 Comparison of different block arrangements. Visualized water discharge process of (a) 2-11×6, and (b) $2-6 \times 11$ at the low air supply rate $(2.1 \mathrm{~m} \mathrm{~s}-1)$.

dot matrix and sloping baffle flow field design, ${ }^{[23]}$ and do experiments through single cell tests, EIS technique and twophase flow visualization. The matrix flow field is compared with the conventional parallel and serpentine flow fields, and effects of the single block area and block arrangement are analyzed. The cell with the matrix flow field presents better performance than that with the conventional parallel and serpentine flow fields, especially at high RH. The current density of the cell with the matrix flow field is $75 \%$ higher than that with the conventional parallel and serpentine flow fields when $\mathrm{V}=0.6 \mathrm{~V}$ and $\mathrm{RH}=100 \%$. Meanwhile, the pressure drop of the cell with the matrix flow field is much less than that with the serpentine flow field. However, 1-4.3-11 shows the worse liquid discharge capacity than the serpentine flow field. Creating sub-regions and compulsive gas distribution should be considered if the matrix flow field is applied in the full scale automotive fuel cells. When the block arrangement is the same, the matrix flow field with the smaller single block shows more remarkable characteristics of the matrix flow field, namely the larger ohmic loss but the smaller activation loss in the investigated range. We infer that refined machining, decreasing the scale of the single block, is helpful to increase the cell performance and reinforce the advantages of the matrix flow field. However, for water discharge, the matrix flow field with the small single block will lead to more water accumulation at the corners of the flow field than that with the large block. And increasing the air supply rate does not help water discharge for the matrix flow field. When the single block area is the same, the matrix flow field with the compacter block arrangement generally shows better performance on both reducing ohmic and activation losses by the large conductive area and enhanced air guidance effect in the investigated range. And the matrix flow fields with different rows and columns (rectangular array, such as $2-11 \times 6$ and 2-6×11) also show much performance difference. The analysis of this work is expected to guide the specific design and application of the proposed matrix flow field.

\section{Acknowledgements}

This research is supported by the National Key Research and Development Program of China (Grant No. 2016YFB0101303), the National Natural Science Foundation of China (grant No. 51920105010), and the Natural Science Foundation of Tianjin (China) for Distinguished Young Scholars (Grant No. 18JCJQJC46700).

\section{Conflict of interest}

There are no conflicts to declare.

\section{Supporting information}

Not applicable

\section{References}

[1] B Liu, Y Jin, G Xie, Z. Wang, H. Wen, N. Ren and D. Xing, ES Energy Environ., 2018, 1, 56-66. doi: 10.30919/esee8c160.

[2] Z Yang, B Wang, K Jiao, Energy, 2020, 198, 117365, doi: 10.1016/j.energy.2020.117365.

[3] Y Wang, B Seo, B Wang, N. Zamel, Kui Jiao, Xavier Cordobes Adroher, Energy AI, 2020, 1, 100014, doi: 10.1016/j.egyai.2020.100014.

[4] T Lin, L Hu, W Wisely, X. Gu, J. Cai, S. Litster, L. Burak Kara, Energy AI, 2021, 3, 100045, doi: 10.1016/j.egyai.2020.100045.

[5] R Xie, R Ma, S Pu, Energy AI, 2020, 2, 100017. doi: 10.1016/j.egyai.2020.100017.

[6] Wang B, Zhang G, Wang H, L. Xu, D. Zhao, Y. Huang, Energy AI, 2020, 1, 100004, doi: 10.1016/j.egyai.2020.100004.

[7] P Trogadas, J I S Cho, T P Neville, Energy Environ. Sci., 2018, 11, 136-143, doi: 10.1039/C7EE02161E. 
[8] L He, M Hou, Y Gao, D Fang, P. Wang. B. Lv, Z. Shao, Energy [21] Y Wang, J. Electrochem. Soc., 2009, 156, B1124, doi: Convers. Manage, $\quad 2020, \quad 205, \quad 112335$, doi: $10.1149 / 1.3183781$. 10.1016/j.enconman.2019.112335.

[22] Y Wang, J. Electrochem. Soc., 2009, 156, B1134-B1141, doi: [9] Z Bao, Z Niu, K Jiao, J. Power Source., 2019, 438, 226995, 10.1149/1.3183785. doi: 10.1016/j.jpowsour.2019.226995.

[10] A Azarafza, M S Ismail, M Rezakazemi, M Pourkashanian, Renew. Sustain. Energy Rev., 2019, 116, 109420, doi: 10.1016/j.rser.2019.109420.

[11] L Xing, Y Xu, Z Penga, Qian Xu H Su, W. Shi F. Barbir, AIChE J, 2020, 66(6), e16957, doi: 10.1002/aic.16957.

[12] Z Wan, W Quan, C Yang, H Yan, X Chen, T Huang, X Wang, S Chan, Energy Convers. Manage., 2020, 205, 112386, doi: 10.1016/j.enconman.2019.112386.

[13] T Wilberforce, E I Hassan, E Ogungbemi, O.I jaodola, F N Khatib, A Durrant, J Thompson, A. Baroutaji, A G Olabi, Renew. Sustain. Energy Rev., 2019, 111, 236-260, doi: 10.1016/j.rser.2019.04.081.

[23] B Wang, W Chen, F Pan, J. Power Source, 2019, 434, 226741, doi: 10.1016/j.jpowsour.2019.226741.

[24] X Sun, X Xie, Z Liu, et al. Int. J. Green Energy, in press.

[25] S C Cho, Y Wang, K S Chen, J. Power Source, 2012, 206, 119-128, doi: 10.1016/j.jpowsour.2012.01.057.

[26] S C Cho, Y Wang, K S Chen, J. Power Source, 2012, 210, 191-197, doi: 10.1016/j.jpowsour.2012.03.033.

[27] X C Adroher, J. Power Source, 2011, 196, 9544-9551, doi: 10.1016/j.jpowsour.2011.07.076.

[28] Y Wang, K S Chen Chem. Eng. Sci., 2011, 66, 3557-3567, doi: 10.1016/j.ces.2011.04.016.

[29] O B Rizvandi, M G Eskin, S Yesilyurt, Int. J. Hydrogen Energy, 2020, 46, 4378-4398, doi: [14] K D Baik, E H Lee, H Yonn, J. Kim, S. Yang, Int. J. Hydrogen Energy, 2019, 44, 25894-25904, doi: 10.1016/j.ijhydene.2019.08.025.

[15] Y Awin, N Dukhan, Appl. Energy, 2019, 252, 113458, doi: 10.1016/j.apenergy.2019.113458.

[16] H Liu, W Yang, J Tan, Y an, S Cheng, fuel cells. Energy Convers. Manage., 2018, 176, 99-109, doi: 10.1016/j.enconman.2018.09.024.

10.1016/j.ijhydene.2020.10.228.

[30] M Ghasabehi, M Ashrafi, M Shams, Fuel, 2021, 285, 119194, doi: 10.1016/j.fuel.2020.119194.

[31] D. Wen, L. Yin, Z. Piao, C Lu, G Li, Q Leng, Int. J. Heat Mass Transf., 2018, 121, 775-787, doi: 10.1016/j.ijheatmasstransfer.2018.01.053.

[32] S A Atyabi, E Afshari, J. Cleaner Produc., 2019, 214, 738748, doi: 10.1016/j.jclepro.2018.12.293.

[17] B H Lim, E H Majlan, W R Daud, Chem. Eng. Sci., 2020, 217, 115499, doi: 10.1016/j.ces.2020.115499.

[18] Y Cai, Z Fang, B Chen, Energy, 2018, 161, 28-37, doi: 10.1016/j.energy.2018.07.127.

[19] J Shen, Z Tu, S H Chan, Appl. Thermal Eng., 2020, 164, 114464, doi: 10.1016/j.applthermaleng.2019.114464.

[20] A Ghanbarian, M J Kermani, J Scholta, M. Abdollahzadeh, Energy Convers. Manage., 2018, 166, 281-296, doi: 10.1016/j.enconman.2018.04.018. 